\title{
Cross-Talk of Atherosclerosis and Ischemic Stroke: Dramatic Role of Neutrophils
}

\author{
Abdolreza Esmaeilzadeh (iD) ${ }^{1,2,{ }^{*}, \text { Maryam Zarerafie }^{3} \text { and Azita Mohammadzadeh }}{ }^{3}$ \\ ${ }^{1}$ Department of Immunology, School of Medicine, Zanjan University of Medical Sciences, Zanjan, Iran \\ ${ }^{2}$ Cancer Gene Therapy Research (CGRC), Zanjan University of Medical Sciences, Zanjan, Iran \\ ${ }^{3}$ School of Medicine, Zanjan University of Medical Sciences, Zanjan, Iran \\ "Corresponding author: Department of Immunology, School of Medicine, Zanjan University of Medical Sciences, Zanjan, Iran. Email: a46reza@zums.ac.ir
}

Received 2020 May 23; Revised 2021 January 02; Accepted 2021 May 03.

\begin{abstract}
Context: Current investigations illustrate the increasing prevalence of atherosclerosis (AS) through the aggravating role of inappropriate lifestyle patterns. Atherosclerosis is the cause of important vascular-related diseases such as ischemic stroke (IS). Understanding AS pathophysiology can help reduce the incidence of AS-mediated diseases like ischemic stroke.

Evidence Acquisition: For this narrative review article, we used the five mega databases of PubMed, Google Scholar, Scopus, Springer, and Science Direct. We searched from 2010 Jan to 2020 Dec and based on keywords and inclusion criteria, 77 articles were enrolled.

Results: Based on prior articles on atherosclerosis and ischemic stroke pathophysiology, local and systemic inflammation is a vigorous factor in both diseasesIndeed, the fundamental inflammatory pathway involved atherosclerosis, and ischemic stroke is associated with the toll-like receptor 4/myeloid differentiation primary response 88/nuclear factor-kappa B (TLR4/ Myd88/NF- $\kappa$ B) cascade. The functional paw of these intricate mechanisms are pro-inflammatory mediators, such as interleukin- 1 beta (IL-1 $\beta$ ), tumor necrosis factor (TNF- $\alpha$ ), and interleukin-18 (IL-18) incite inflammation. Besides, the essential structures termed inflammasomes (multi proteins components), and multiplicity of immune and non-immune cells (i.e., neutrophils, monocytes, platelets, and macrophages) are beneficial in the induction of inflammatory microenvironment.

Conclusions: Neutrophils could be the most effective cells in the inflammation-based mechanism in IS and AS. It is clarified that neutrophils with the recruitment of own vesicles and granules can afford to amplify inflammatory conditions and be a key cell in AS and IS cross-talk. Therefore, utilizing methods to control neutrophils-mediated mechanisms could be an effective method for the prevention of AS and IS.
\end{abstract}

Keywords: Atherosclerosis, Ischemic Stroke, Neutrophil, NeXosome, Inflammasome

\section{Context}

Two of the significant challenges in the world include atherosclerosis and stroke, which are the focus of this study. Stroke is one of the significant reasons for death and disability and is divided into ischemic and hemorrhagic types. Of these, the most common is the ischemic type. The general mechanism of ischemic stroke (IS) is based on vascular obstruction and a series of cellular and molecular events leading to the symptoms and progression of the disease. Neutrophils, monocytes, macrophages, and platelets play an important role in this process due to their influence on cytokine production that appoints an inflammatory environment. Inflammation and its progression can induce ischemia. There is a continuity cycle between ischemia and inflammation that leads to stroke. In this process, inflammatory cells are essential members. The details have been elucidated in former studies (1-14)

Atherosclerosis (AS) is a common vascular disorder that has a devastating impact on human health and leads to life-threatening conditions such as stroke, myocardial infarction, and hypertension. Therefore, AS results in high mortality and morbidity rates. The main reason for AS is high-saturated fat diets, but this is not all, and there are cellular and molecular mechanisms that induce AS (2-5, 7, 15 $24)$. Given the role and importance of cellular and molecular mechanisms in ischemic stroke and AS, we considered it necessary to address these mechanisms in our study.

\section{Evidence Acquisition}

For this narrative article, first we searched the five mega databases of PubMed, Google Scholar, Scopus, 
Springer, and Science Direct using "Atherosclerosis", "Ischemic stroke", "Neutrophil", "NeXosome", and "Inflammasome" as our selected keywords. We searched for all related articles from 2010 Jan to 2020 Dec, and overall, 77 articles were ultimately enrolled.

\section{Results}

\subsection{Pathogenesis of Atherosclerosis}

The atherosclerotic plaque consists of endothelial cells, macrophages, and smooth muscle cells of the arteries. The formation of this plaque is due to the disruption of the fat profile and an increase in the serum level of apolipoprotein B100 (APO B100). This molecule enters the sub-endothelial region of the arteries. Among the mechanisms involved in this process are the immune system and pro-inflammatory molecules. In general, the immune system responds to components that are not in the normal position. Following the placement of an apo B100 in the subendothelial region of the arteries, the immune system activates and attempts to eliminate these molecules through cellular and molecular chains. Nevertheless, due to structural changes in the entering apo B100, the immune system fails, and this initiates a series of molecular and cellular chains to form and promote the development of atherosclerotic plaque (Figure 1) $(2,5,7,14,21-37)$.

\subsubsection{Molecular Mechanism of Atherosclerosis}

As mentioned above, different molecular mechanisms are involved in atherosclerosis, and the preliminary one is apo B100 infiltrating the atherogenic site. Upon the entrance of apo B100, molecular changes occur during the oxidation and glycation processes in this component, preventing its exertion from the region and returning to the bloodstream. The increased expression of vascular cell adhesion molecule (VCAM) and intercellular adhesion molecule (ICAM) on the endothelial cell surface is an essential change in atherosclerosis. These two molecules are necessary for the migration of inflammatory cells to the target tissue $(24,26,27,32-38)$.

Another molecular direction is due to the secretion of macrophage-mediated chemokines such as chemokine (CC motif) ligand 3 (CCL3), monocyte chemoattractant protein (MCP1), and chemokine (C-C motif) ligand 5 (CCL5). These chemokines bind to monocytes as a ligand and stimulate the entry of these cells into the subendothelium and apo B100 accumulation site. Since this aggregation is considered an abnormal phenomenon, it requires to be eliminated. In natural conditions, the removal of abnormal aggregates is the responsibility of macrophages, which occurs as a result of macrophage entry into the tissue (Figure 1). After entering the tissue, macrophages begin to devour the apo B100 for cleaning. However, because of the reduction of the C-C chemokine receptor type 7 (CCR7) expression in these cells, instead of cleaning, foam cell is formed and remains in the tissue. Also, the foam cell-secreted CCL3 factor by connecting to its particular receptor on the neutrophil surface can afford margination and migration into the atherosclerotic plaque site (22, 24, 26, 27, 32-39).

Due to the presence of these immune cells in the target tissue, an inflammatory microenvironment is created that initiates an inflammatory cascade. One of the early and essential members of the TLR4/MyD88/NF- $\kappa \mathrm{B}$ chain is the expression of TLR4, which ultimately results in MyD88 activation that stimulates the NF- $\kappa$ B pathway. Due to this pathway, inflammatory factors such as IL-1 $\beta$, TNF- $\alpha$, and IL-18 are produced and result in inflammasome production. Inflammasomes are composed of multiprotein components that have a proven role in the inflammatory response. One of the imperative members is the NOD-like receptor family, pyrin domain containing 3 (NLRP3) that is implicated in inducing inflammation by increasing the transcription of pro-inflammatory cytokines, such as proIL-1 $\beta$, TNF- $\alpha$, and pro-IL-18, and converting pro-caspase- 1 to the active form. Caspase- 1 can activate pro-IL- $\beta$ and proIL-18 during proteolysis (22, 26, 27, 33, 39-45). Another imperative factor in NLRP3 activation is through the direct effect of cholesterol crystals on inflammasomes that follow a similar pathway as indirect activation of this inflammatory component. These sets of mechanisms induce an inflammatory condition in the target tissue $(22,25-29,40,46$ 48).

Also, complement proteins are critical in AS. The mechanism involved is the increased expression of complement receptors and complement activators $\left(C_{1 q}, C_{3}\right)$ by damaged cells present in the ischemic lesion (49-53). These components can act both directly and indirectly. In the direct method, they motivate phagocytosis by cell lysis, while in the indirect method, the expression of adhesion and chemotactic molecules is increased, resulting in the activation of leukocytes such as neutrophils. Overall, they aggravate the cellular locomotion to the ischemic site and further promote inflammation (Figure 2) (49-55).

\subsubsection{The Cellular Mechanism in Atherosclerosis}

As mentioned before, a cellular complex is implicated in atherosclerosis pathophysiology, which is described in detail below.

\subsubsection{The Role of Neutrophils}

Neutrophils are crucial polymorphonuclear granulocytes in host defense that rise in ischemic stroke and are associated with disease prognosis (1). These are hematopoietic-derived immune cells with multiple phenotypes (No, N1, and N2) in different tissues with diverse 


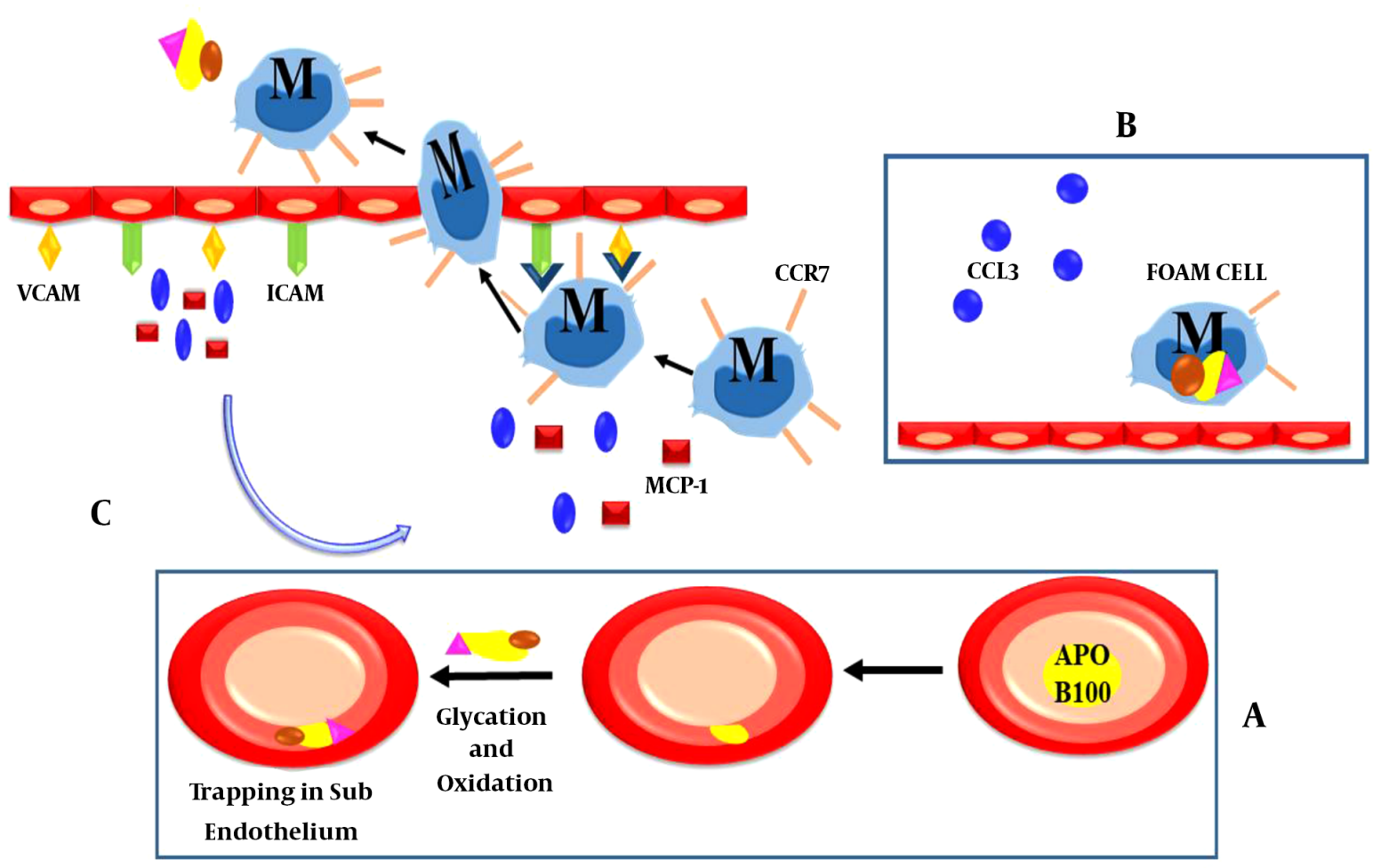

Created by Dr. Esmaeilzadeh and et al.

Figure 1. A and C, vascular cell adhesion molecule (VCAM) and intercellular adhesion molecule (ICAM) expression on the endothelial cell surface is an essential change in atherosclerosis. These two molecules are necessary for the migration of inflammatory cells to the target tissue. Another molecular direction is due to the secretion of macrophage-mediated chemokines such as chemokine (C-C motif) ligand 3 (CCL3), monocyte chemoattractant protein (MCP1), and chemokine (C-C motif) ligand 5 (CCL5). These chemokines bind to monocytes as a ligand and stimulate these cells' entry into the subendothelium and the apo B100 accumulation site. Binding of CD18 on NMVs to ICAM-1 on epithelial cells results in neutrophil microvesicles activation and function. Leukocytes extravasation into the ischemic region increases through the enhanced expression of ICAM-1, VCAM-1, and CCL2 in epithelial cells; B, after entering the tissue, macrophages begin to devour apo B100 for cleaning. The reduction of the C-C chemokine receptor type 7 (CCR7) expression in these cells causes foam cell formation.

pathologic situations, such as cancer, inflammation, infection, and metabolism. Neutrophils are rarely found in lesions, and most of their efficacy is via their granules and vesicles. These cells have a variety of granules that are categorized into the four general groups of azurophilic granules, specific granules, gelatinase granules, and secretory vesicles $(1,7,13,15,21,56-61)$. Each of these has a particular function in terms of their contents.

One of the mentioned types is secretory vesicles that are essential for atherosclerosis and stroke (7, 21, 59-63). Also, neutrophils release specific components called microvesicles containing numerous substances that can influence the environment and other cells. It can the immune system regulation and inflammatory responses such as cell stimulation, induction of protein transfer, and presenting peptide antigens $(1,7,21,56,58-60,62-64)$. Other types of neutrophil vesicles include nano-vesicles named exosomes or NeXosomes.

NeXosomes have specific proteins related to the ori- gin tissue. They also have several numbers of standard components, signal transduction kinases, including heat shock proteins (HSPs) -27,-70, and-90, adhesion molecules, such as integrin and tetraspanins (CD9 and CD63), and members of the endosomal sorting complexes required for transport (ESCRT) complex. Furthermore, some of these proteins have a function in signal transduction and translocation of proteins, mRNA, and microRNA (miRNA) by binding to adhesion molecules $(1,7,21,56-60,62-$ $66)$. Another sort of neutrophilic vesicles is a microvesicle that does most of the neutrophil activity. Therefore, neutrophils can influence vascular inflammation and atherosclerotic plaque promotion without entering the vessel wall $(26,56,58-60,62,63,66)$. On the other hand, it has been found that the amount of microvesicle secretion is related to diet. In the presence of a high-fat diet, these microvesicles excrete and attach to atheroprone sites of vessels that afford monocytes to enter. Under these events, monocytes convert to macrophages, and by ingesting the 


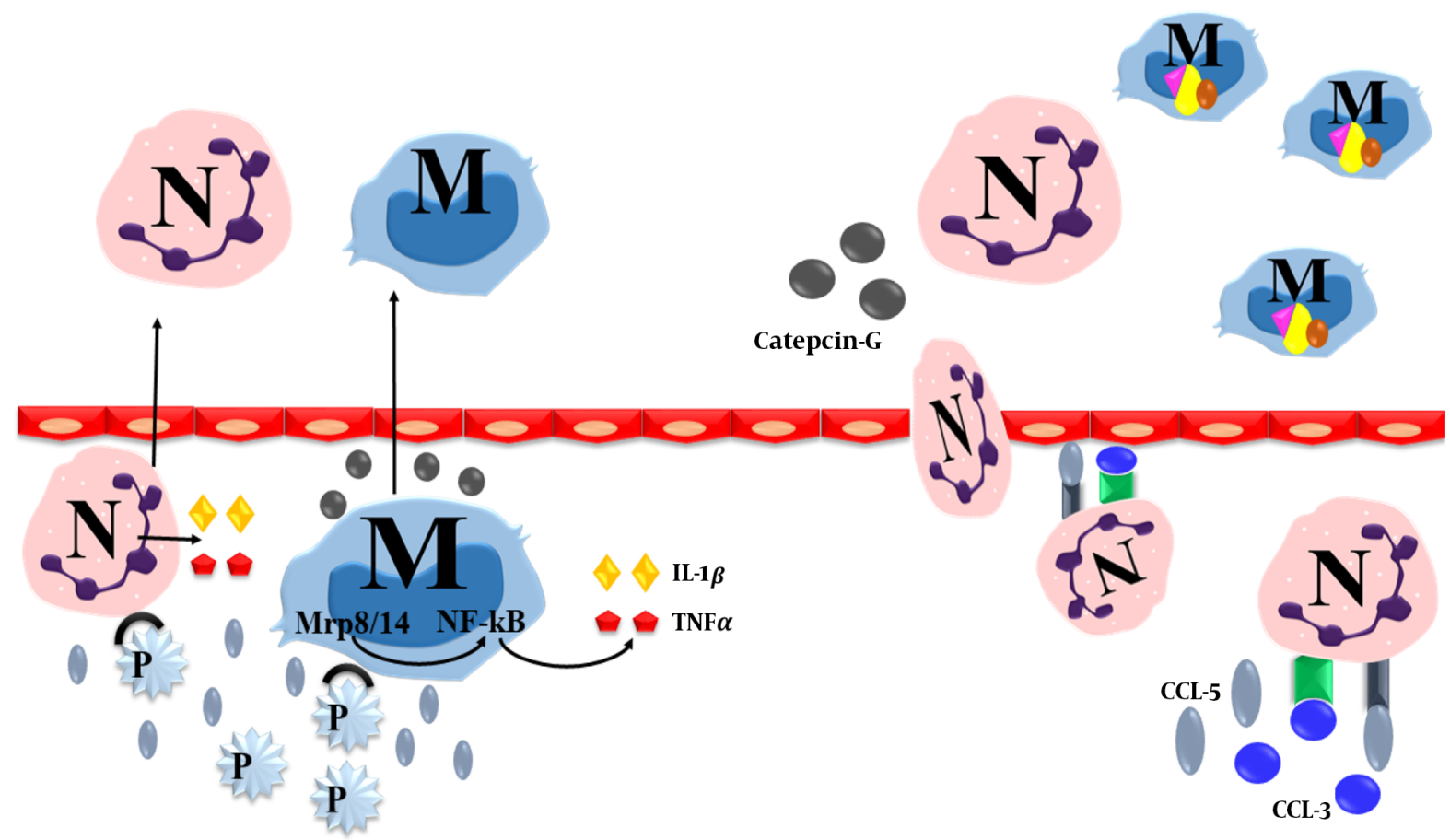

Created by Dr. Esmaeilzadeh and et al.

Figure 2. The foam cell-secreted CCL3 factor connects to its particular receptor on the neutrophil surface and affords this cell's margination and migration into the atherosclerotic plaque site. The TLR4/MyD88/NF- $\kappa$ B chain results in IL-1 $\beta$, TNF- $\alpha$, and IL-18 production.

fat content, cholesterol level increases in myeloid cells, resulting in the activation of NLRP3 and an increase in neutrophil accumulation $(26,40,41,48,56,58-64,67,68)$. This function of neutrophil microvesicles (NMVs) requires their activation depending on the binding of CD18 on NMVs to ICAM-1 on epithelial cells.

With respect to the enhanced expression of ICAM-1, VCAM-1, and CCL2 in epithelial cells, leukocyte extravasation into the ischemic region will increase. These changes upturn the expression of miRNAs such as miR-155 in NMVs, which affect gene expression on epithelial cells. miR-155 reduces the expression of Bcl-6. Since Bcl-6 is an inhibitor of NF- $\kappa \mathrm{B}$, miR-155 enhanced the expression of NF- $\kappa \mathrm{B}(21,25-27$, $42,44,56,58-60,63,65,66)$. Meanwhile, NF- $\kappa$ B is a critical member of the inflammatory pathway in the atheroma and monocyte extravasation. In the next step, the inflammation at the plaque site is promoted. In general, neutrophils have a crucial role in the atherosclerotic inflammatory process $(25,26,42,44,58-60,62)$.

3.1.2.2. Cross Talk of Platelets, Neutrophils, and Atherosclerosis

As mentioned, another cell type involved in the atherosclerotic processes is platelets termed immune regulating cells. The main event involves a set of cells and molecules interconnected through surface receptors and inflammatory cytokines. Platelets exert their influence through molecular mechanisms and pro-inflammatory pathways stimulation. On the platelet surface, there are molecules called P-selectin, which are one of the essential components inducing the platelet's pro-inflammatory effect. P-selectin binds to P-selectin glycoprotein-1 (PSGL-1) on the surface of agranulocytes (monocytes and lymphocytes) and neutrophils and initiates the pro-inflammatory role of platelets in pathways leading to atherosclerosis (1, $26,53,56,62,69-73)$.

In neutrophils and monocytes, several cytoplasmic proteins are involved in the progression of inflammatory pathway present in atherosclerosis, including, Mrp1 and Mrp14. These two proteins function both individually and as heterodimers. This heterodimer form (Mrp-1/ Mrp-14) regulates the binding of these cells to the vascular endothelium by regulating the $\beta_{2}$ integrin-mediated rolling process. They act as endogenous activators of TLR$4 / \mathrm{MyD} 88 / \mathrm{NF}-\kappa \mathrm{B}$ downstream that induce inflammation, as previously mentioned. With regard to former studies, this heterodimer is released following integration with activated monocytes and inflammatory cytokines such as TNF$\alpha$. Another stimulator of the secretion of inflammatory cytokines is the interaction between P-selectin and PSGL-1 in 
neutrophils. An additional known function of platelets is the release of chemokines called CCL5 that bind to CCR5 on monocytes and amplified platelets entering into the subendothelial tissue $(6,27,42,44,53,62,69-73)$. Referring to the above, there is a cross-talk between platelet and neutrophils that is critical in the atherosclerosis inflammatory process.

\subsection{Atherosclerosis and Ischemic Stroke}

In cooperation with all the mentioned mechanisms, the atherosclerotic plaque is formed. This plaque can develop in any artery, but the main treatment is related to large arteries like the carotid that is the central part of the blood supply to the brain. As the plaque encroaches the vessel lumen, blood supply becomes limited. Now, there is a danger of complete obstruction of the vessel via clot formation. Plaque rupture initiates platelet adhesion and aggregation on the lesion and the activation of the coagulation cascade that can deprive blood supply in the target tissue by complete occlusion $(2,22,23)$. Then, a sequence of cellular and molecular reactions contributes to systemic and focal inflammation. The primary starter of inflammation in ischemic stroke is the damage-associated molecular pattern (DAMPs) produced by neuronal and non-neuronal dead cells present in the brain. These molecular patterns are based on pattern recognition receptors (PRRs) $(20,23$, $25,26,74)$.

Damage-associated molecular patterns are a series of endogenous molecules involved in the development of the stroke process and elicit an immune response. On the other hand, they can activate endothelial cells and increase the expression of VCAM-1, ICAM-1, and E-selectin, and promote leukocyte extravasation $(20,25-27,74)$. Pattern recognition receptors include TLRs and NOD-like receptor family (NLRs), which are innate immune molecules expressed by microglia, astrocytes, monocytes, macrophages, neutrophils, and other cells binding to DAMPS. After binding, microglia in the injured region are rapidly activated. Then, a group of hematogenous immune cells invades the ischemic brain tissue. One of the critical cells are neutrophils, and among the different types of neutrophils, the $\mathrm{N} 2$ phenotype is less harmful to ischemic stroke and does not induce neuronal cell death in comparison with No or N1 phenotypes. Also, the frequency of N2 in the peripheral blood flow is a predisposing factor for ischemic stroke consequences. As previously described, other prominent parts of the underlying mechanism in ischemic stroke are PRRs. Some of these PRRs are related to inflammasomes. Among these components, only a part of them is pivotal in stroke-induced inflammation, such as NLRP-1, NLRP-3, and absent in melanoma 2 (AIM2) $(1,20,25-28,31,74,75)$. Inflammasomes are activated through decreasing $\mathrm{pH}$ following ischemia-induced respiration, ROS, cathepsin, and potassium channels, as described in detail below.

\subsection{1. pH Reduction}

The block of brain bloodstream evinces metabolism and converts to anaerobic type. Then, the amount of ATP produced by mitochondria excessively induces lactic acidosis and decreases $\mathrm{pH}$. After the lack of energy to reabsorb neurotransmitters at synaptic zones, a neuronal function is disrupted. On the other hand, $\mathrm{pH}$ reduction can enhance NLRP3 receptors, and enhance the inflammasome effect. With this interpretation, $\mathrm{pH}$ regression can be a trigger of inflammation and ischemia that contribute to stroke (20, 26-28, 31, 40, 41, 68, 74, 76).

\subsubsection{Cathepsin Releases}

Cathepsin release following atherosclerotic plaque rupture is deemed to activate NLRP-3 and NLRP-1. Interleukin-1 $\beta$ and IL-18 production undergo procaspase-1 downstream function and can subsequently induce an inflammatory microenvironment $(20,26-28,31,74,76)$.

\subsubsection{Potassium Channel Function}

Another process of NLRP3 activation is via potassium channels embedded in the cell membrane. These channels usually function as a conduit for potassium ion mobilization that induces proportion on both sides of the cell membrane. It is demonstrated that potassium excretion is worsened by ischemia-induced acidosis (20, 26-28, 31, 40, 41, 48, $68)$. Secondary to all the mechanisms mentioned, NLRP3 is activated. This functional form contributes to pro-caspase1 activation through NF- $\kappa$ B and MAPK pathways. The next step is converting inactivating precursors of IL-1 $\beta$ and IL18 to their mature forms by caspase-1 during the proteolysis process. The release of these mediators leads to an ensuing systemic inflammation. It indicates a round of succession between the promotion of inflammation and ischemia, which cooperatively induce a sustained destructive brain cycle $(27,28,40-42,44,68)$.

\section{Conclusions}

Atherosclerosis and ischemic stroke are multifactorial diseases, and various cellular mechanisms are involved in this pathogenesis, including neutrophils, platelets, monocytes, and macrophages. The function of the mentioned cells is based on molecules' application, including inflammasomes, cytokines, cell membrane channels, secretory vesicles, and the TLR4/ Myd88/ NF- $\kappa$ B pathway. The correlation and continuity between these cells and molecules form the core of the progression of these diseases. On the other hand, neutrophils play a more fundamental role in 
all the stages of these two diseases. Therefore, it can be concluded that specific targeting of this cell can have a unique effect on treating these diseases. Indeed, the cells and mechanisms described above are related to neutrophils. This study shed light on the importance of the neutrophils' role in the aggravation of the inflammatory process of atherosclerosis and ischemic stroke immunopathogenesis. Therefore, it is hoped that molecular and cellular interactions can optimize the therapeutic response in ischemic stroke.

\section{Footnotes}

Authors' Contribution: Abdolreza Esmaeilzadeh, conceptualization qualifying, theoretical and academic revision, project administration, and definitive approval of the final manuscript; Maryam Zare Rafie and Azita Mohammadzadeh, main conceptualization, data collection, conclusive literature review, scientific writing (last draft of manuscript preparation), and image preparation. All the authors have approved the final version of the article.

Conflict of Interests: The authors declare no conflicts of interest in the manuscript.

Funding/Support: There was no funding for the present manuscript.

\section{References}

1. Kollikowski AM, Schuhmann MK, Nieswandt B, Mullges W, Stoll G, Pham M. Local leukocyte invasion during hyperacute human ischemic stroke. Ann Neurol. 2020;87(3):466-79. doi: 10.1002/ana.25665. [PubMed: 31899551].

2. Jansen MF, Lutgens E, Daemen MJAP. Atherosclerosis of the carotid artery. Vessel based imaging techniques. Berlin, Germany: Springer; 2020. p. 69-91.

3. Krishnamurthi RV, Barker-Collo S, Parag V, Parmar P, Witt E, Jones A, et al. Stroke incidence by major pathological type and ischemic subtypes in the auckland regional community stroke studies: Changes between 2002 and 2011. Stroke. 2018;49(1):3-10. doi: 10.1161/STROKEAHA.117.019358. [PubMed: 29212738].

4. Li D, Wang C, Yao Y, Chen L, Liu G, Zhang R, et al. mTORC1 pathway disruption ameliorates brain inflammation following stroke via a shift in microglia phenotype from M1 type to M2 type. FASEB J. 2016;30(10):3388-99. doi:10.1096/fj.201600495R. [PubMed: 27342766].

5. Flores AM, Hosseini-Nassab N, Jarr KU, Ye J, Zhu X, Wirka R, et al. Pro-efferocytic nanoparticles are specifically taken up by lesional macrophages and prevent atherosclerosis. Nat Nanotechnol. 2020;15(2):154-61. doi: 10.1038/s41565-019-0619-3. [PubMed: 31988506]. [PubMed Central: PMC7254969].

6. Ao LY, Yan YY, Zhou L, Li CY, Li WT, Fang WR, et al. Immune cells after ischemic stroke onset: Roles, migration, and target intervention. J Mol Neurosci. 2018;66(3):342-55. doi: 10.1007/s12031-018-1173-4. [PubMed: 30276612].

7. Silvestre-Roig C, Braster Q, Ortega-Gomez A, Soehnlein O. Neutrophils as regulators of cardiovascular inflammation. Nat Rev Cardiol. 2020;17(6):327-40. doi: 10.1038/s41569-019-0326-7. [PubMed: 31996800].

8. Donkor ES. Stroke in the 21(st) Century: A snapshot of the burden, epidemiology, and quality of life. Stroke Res Treat. 2018;2018:3238165. doi: 10.1155/2018/3238165. [PubMed: 30598741]. [PubMed Central: PMC6288566].

9. Yang SO, Nielsen GH, Wilding KM, Cooper MA, Wood DW, Bundy BC. Towards on-demand E. coli-based cell-free protein synthesis of tissue plasminogen activator. Methods Protoc. 2019;2(2):52. doi: $10.3390 / \mathrm{mps} 2020052$.

10. Boehme AK, Esenwa C, Elkind MS. Stroke risk factors, genetics, and prevention. Circ Res. 2017;120(3):472-95. doi: 10.1161/CIRCRESAHA.116.308398. [PubMed: 28154098]. [PubMed Central: PMC5321635].

11. Katan M, Luft A. Global burden of stroke. Semin Neurol.2018;38(2):20811. doi: 10.1055/s-0038-1649503. [PubMed: 29791947].

12. Venketasubramanian N, Yoon BW, Pandian J, Navarro JC. Stroke epidemiology in south, east, and south-east asia: A review. J Stroke. 2017;19(3):286-94. doi: 10.5853/jos.2017.00234. [PubMed: 29037005] [PubMed Central: PMC5647629].

13. Jayaraj RL, Azimullah S, Beiram R, Jalal FY, Rosenberg GA. Neuroinflammation: Friend and foe for ischemic stroke. J Neuroinflammation. 2019;16(1):142. doi: 10.1186/s12974-019-1516-2. [PubMed: 31291966]. [PubMed Central: PMC6617684].

14. Herrero-Fernandez B, Gomez-Bris R, Somovilla-Crespo B, Gonzalez Granado JM. Immunobiology of atherosclerosis: A complex net of interactions. Int J Mol Sci. 2019;20(21). doi: 10.3390/ijms20215293. [PubMed: 31653058]. [PubMed Central: PMC6862594].

15. Ramiro L, Simats A, Garcia-Berrocoso T, Montaner J. Inflammatory molecules might become both biomarkers and therapeutic targets for stroke management. Ther Adv Neurol Disord. 2018;11:1756286418789340. doi: 10.1177/1756286418789340. [PubMed: 30093920]. [PubMed Central: PMC6080077].

16. Alishahi M, Farzaneh M, Ghaedrahmati F, Nejabatdoust A, Sarkaki A, Khoshnam SE. NLRP3 inflammasome in ischemic stroke: As possible therapeutic target. Int J Stroke. 2019;14(6):574-91. doi: 10.1177/1747493019841242. [PubMed:30940045].

17. Jin R, Yang G, Li G. Inflammatory mechanisms in ischemic stroke: Role of inflammatory cells. J Leukoc Biol. 2010;87(5):77989. doi: 10.1189/jlb.1109766. [PubMed: 20130219]. [PubMed Central: PMC2858674].

18. Dugue R, Nath M, Dugue A, Barone FC. Roles of pro- and antiinflammatory cytokines in traumatic brain injury and acute ischemic stroke. In: Aranda Abreu GE, editor. Mechanisms of Neuroinflammation. London, UK: IntechOpen; 2017.

19. Lee JH, Wei ZZ, Cao W, Won S, Gu X, Winter M, et al. Regulation of therapeutic hypothermia on inflammatory cytokines, microglia polarization, migration and functional recovery after ischemic stroke in mice. Neurobiol Dis. 2016;96:248-60. doi: 10.1016/j.nbd.2016.09.013. [PubMed: 27659107]. [PubMed Central: PMC5161414].

20. Hermann DM, Kleinschnitz C, Gunzer M. Role of polymorphonuclear neutrophils in the reperfused ischemic brain: Insights from cell-type-specific immunodepletion and fluorescence microscopy studies. Ther Adv Neurol Disord. 2018;11:1756286418798610. doi: 10.1177/1756286418798607. [PubMed: 30245743]. [PubMed Central: PMC6144496].

21. Zhang X, Hou XH, Ma YH, Shen XN, Cao XP, Song JH, et al. Association of peripheral neutrophil count with intracranial atherosclerotic stenosis. BMC Neurol. 2020;20(1):65. doi: 10.1186/s12883-020-01641-3. [PubMed: 32087674]. [PubMed Central: PMC7035752].

22. Moriya J. Critical roles of inflammation in atherosclerosis. J Cardiol. 2019;73(1):22-7. doi: 10.1016/j.jjcc.2018.05.010. [PubMed: 29907363].

23. Wolf MP, Hunziker P. Atherosclerosis: Insights into vascular pathobiology and outlook to novel treatments. J Cardiovasc Transl Res. 2020;13(5):744-57. doi: 10.1007/s12265-020-09961-y. [PubMed: 32072564].

24. Tabas I. 2016 Russell ross memorial lecture in vascular biology: Molecular-cellular mechanisms in the progression of atherosclerosis. Arterioscler Thromb Vasc Biol. 2017;37(2):183-9. doi: 10.1161/ATVBAHA.116.308036. [PubMed: 27979856]. [PubMed Central: PMC5269511]. 
25. Epelman S, Liu PP, Mann DL. Role of innate and adaptive immune mechanisms in cardiac injury and repair. Nat Rev Immunol. 2015;15(2):117-29. doi: 10.1038/nri3800. [PubMed: 25614321]. [PubMed Central: PMC4669103].

26. Doring Y, Drechsler M, Soehnlein O, Weber C. Neutrophils in atherosclerosis: From mice to man. Arterioscler Thromb Vasc Biol. 2015;35(2):288-95. doi: 10.1161/ATVBAHA.114.303564. [PubMed: 25147339].

27. Shah PK. Inflammation, infection and atherosclerosis. Trends Cardiovasc Med. 2019;29(8):468-72. doi: 10.1016/j.tcm.2019.01.004. [PubMed: 30733074]

28. Tall AR, Westerterp M. Inflammasomes, neutrophil extracellular traps, and cholesterol. J Lipid Res. 2019;60(4):721-7. doi: 10.1194/jlr.S091280. [PubMed: 30782961]. [PubMed Central: PMC6446695]

29. Esmaeilzadeh A, Pouyan S, Erfanmanesh M. Is Interleukin-38 a key player cytokine in atherosclerosis immune gene therapy? Med Hypotheses. 2019;125:139-43. doi: 10.1016/j.mehy.2019.02.048. [PubMed: 30902143]

30. Cochran BJ, Pinheiro D, Prendecki M, Jones B, Cegla J, Lee V, et al. Abstract 609: Pro-atherosclerotic low-density neutrophils are present in hypercholesterolemia.Arterioscler Thromb Vasc Biol. 2018;38(Suppl_1). doi:10.1161/atvb.38.suppl_1.609.

31. Kattoor AJ, Pothineni NVK, Palagiri D, Mehta JL. Oxidative stress in atherosclerosis. Curr Atheroscler Rep. 2017;19(11):42. doi:10.1007/s11883017-0678-6. [PubMed: 28921056].

32. Tabas I, Lichtman AH. Monocyte-macrophages and T cells in atherosclerosis. Immunity. 2017;47(4):621-34. doi 10.1016/j.immuni.2017.09.008. [PubMed: 29045897]. [PubMed Central: PMC5747297].

33. Taleb S. Inflammation in atherosclerosis. Arch Cardiovasc Dis 2016;109(12):708-15. doi: 10.1016/j.acvd.2016.04.002. [PubMed 27595467].

34. Chistiakov DA, Bobryshev YV, Orekhov AN. Macrophage-mediated cholesterol handling in atherosclerosis. J Cell Mol Med. 2016;20(1):1728. doi: 10.1111/jcmm.12689. [PubMed: 26493158]. [PubMed Central: PMC4717859].

35. Boren J, Williams KJ. The central role of arterial retention of cholesterol-rich apolipoprotein-B-containing lipoproteins in the pathogenesis of atherosclerosis: A triumph of simplicity. Curr Opin Lipidol. 2016;27(5):473-83. doi: 10.1097/MOL.0000000000000330. [PubMed: 27472409]

36. Shapiro MD, Fazio S. Apolipoprotein B-containing lipoproteins and atherosclerotic cardiovascular disease. F1000Res. 2017;6:134 doi: 10.12688/f1000research.9845.1. [PubMed: 28299190]. [PubMed Central: PMC5310383]

37. Morita SY. Metabolism and modification of apolipoprotein Bcontaining lipoproteins involved in dyslipidemia and atherosclerosis. Biol Pharm Bull. 2016;39(1):1-24. doi: 10.1248/bpb.b15-00716. [PubMed: 26725424]

38. Linton MRF, Yancey PG, Davies SS, Jerome WG, Linton EF, Song WL, e al. The role of lipids and lipoproteins in atherosclerosis. In: Feingold KR, Anawalt B, Boyce A, Chrousos G, de Herder WW, Dhatariya K, et al., editors. Endotext. South Dartmouth(MA), USA: MDText.com Inc; 2000

39. Chistiakov DA, Grechko AV, Myasoedova VA, Melnichenko AA, Orekhov AN. The role of monocytosis and neutrophilia in atherosclerosis. J Cell Mol Med. 2018;22(3):1366-82. doi: 10.1111/jcmm.13462. [PubMed: 29364567]. [PubMed Central: PMC5824421].

40. Yang Y, Wang H, Kouadir M, Song H, Shi F. Recent advances in the mechanisms of NLRP3 inflammasome activation and its inhibitors. Cell Death Dis. 2019;10(2):128. doi: 10.1038/s41419-019-1413-8. [PubMed 30755589]. [PubMed Central: PMC6372664].

41. Prochnicki T, Mangan MS, Latz E. Recent insights into the molecular mechanisms of the NLRP3 inflammasome activation. F1000Res 2016;5:1469. doi: 10.12688/fioooresearch.8614.1. [PubMed: 27508077] [PubMed Central: PMC4963208].

42. Liu T, Zhang L, Joo D, Sun SC. NF-kappaB signaling in inflammation. Signal Transduct Target Ther. 2017;2. doi: 10.1038/sigtrans.2017.23.
[PubMed: 29158945]. [PubMed Central: PMC5661633].

43. Zhu S, Tang S, Su F. Dioscin inhibits ischemic strokeinduced inflammation through inhibition of the TLR4/MyD88/NFkappaB signaling pathway in a rat model. Mol Med Rep. 2018;17(1):660-6. doi: 10.3892/mmr.2017.7900. [PubMed: 29115455].

44. Fann DY, Lim YA, Cheng YL, Lok KZ, Chunduri P, Baik SH, et al. Evidence that NF-kappaB and MAPK signaling promotes NLRP inflammasome activation in neurons following ischemic stroke. $\mathrm{Mol} \mathrm{Neu}$ robiol. 2018;55(2):1082-96. doi: 10.1007/s12035-017-0394-9. [PubMed: 28092085].

45. Zhang Y, Liu F, Yuan Y, Jin C, Chang C, Zhu Y, et al. Inflammasomederived exosomes activate NF-kappaB signaling in macrophages. $J$ Proteome Res. 2017;16(1):170-8. doi: 10.1021/acs.jproteome.6b00599. [PubMed: 27684284].

46. Ahmadi F, Esmaeilzade A. IL-1R2: A novel approach for gene therapy in atherosclerosis. Hypothesis. 2016;14(1). doi: 10.5779/hypothesis.v14i1.456.

47. Khosh E, Bahmaie N, Elahi R, Esmaeilzadeh A. Clinical applications of interleukin-37: A key player in the immunopathogenesis of immune disorders. Iran J Allergy Asthma Immunol.2020;19(3):209-28. doi: 10.18502/ijaai.v19i3.3450. [PubMed:32615656]

48. He Y, Hara H, Nunez G. Mechanism and regulation of NLRP3 inflammasome activation. Trends Biochem Sci. 2016;41(12):1012-21. doi: 10.1016/j.tibs.2016.09.002. [PubMed: 27669650]. [PubMed Central: PMC5123939].

49. Pilely K, Fumagalli S, Rosbjerg A, Genster N, Skjoedt MO, Perego C, et al. C-reactive protein binds to cholesterol crystals and co-localizes with the terminal complement complex in human atherosclerotic plaques. Front Immunol. 2017;8:1040. doi: 10.3389/fimmu.2017.01040. [PubMed: 28900428]. [PubMed Central: PMC5581807].

50. Fumagalli S, Perego C, Zangari R, De Blasio D, Oggioni M, De Nigris $\mathrm{F}$, et al. Lectin pathway of complement activation is associated with vulnerability of atherosclerotic plaques. Front Immunol. 2017;8:288. doi: 10.3389/fimmu.2017.00288. [PubMed: 28360913]. [PubMed Central: PMC5352714].

51. Ge X, Xu C, Liu Y, Zhu K, Zeng H, Su J, et al. Complement activation in the arteries of patients with severe atherosclerosis. Int JClin Exp Pathol. 2018;11(1):1-9. [PubMed: 31938082]. [PubMed Central: PMC6957963].

52. Martin-Ventura JL, Martinez-Lopez D, Roldan-Montero R, GomezGuerrero C, Blanco-Colio LM. Role of complement system in pathological remodeling of the vascular wall. Mol Immunol. 2019;114:207-15. doi: 10.1016/j.molimm.2019.06.016. [PubMed: 31377677].

53. Kim H, Conway EM. Platelets and complement cross-talk in early atherogenesis. Front Cardiovasc Med. 2019;6:131. doi: 10.3389/fcvm.2019.00131. [PubMed: 31555668]. [PubMed Central: PMC6742699].

54. Vlaicu SI, Tatomir A, Rus V, Mekala AP, Mircea PA, Niculescu F, et al. The role of complement activation in atherogenesis: The first 40 years. Immunol Res. 2016;64(1):1-13. doi: 10.1007/s12026-015-8669-6. [PubMed: 26091721].

55. An G, Ren G, An F, Zhang C. Role of C5a-C5aRaxis in the development of atherosclerosis. Sci China Life Sci. 2014;57(8):790-4. doi: 10.1007/s11427014-4711-5. [PubMed: 25104451].

56. Lim HH, Jeong IH, An GD, Woo KS, Kim KH, Kim JM, et al. Evaluation of neutrophil extracellular traps as the circulating marker for patients with acute coronary syndrome and acute ischemic stroke. J Clin Lab Anal. 2020;34(5). e23190. doi: 10.1002/jcla.23190. [PubMed: 31907963]. [PubMed Central: PMC7246366].

57. Cai W, Liu S, Hu M, Huang F, Zhu Q, Qiu W, et al. Functional dynamics of neutrophils after ischemic stroke. Transl Stroke Res. 2020;11(1):10821. doi: 10.1007/s12975-019-00694-y. [PubMed: 30847778]. [PubMed Central: PMC6993940].

58. Moschonas IC, Tselepis AD. The pathway of neutrophil extracellular traps towards atherosclerosis and thrombosis. Atherosclerosis. 2019;288:9-16. doi: 10.1016/j.atherosclerosis.2019.06.919. [PubMed: 31280097].

59. Bonaventura A, Liberale L, Carbone F, Vecchie A, Diaz-Canestro C, Cam- 
ici GG, et al. The pathophysiological role of neutrophil extracellular traps in inflammatory diseases. Thromb Haemost. 2018;118(1):6-27. doi: 10.1160/TH17-09-0630. [PubMed: 29304522].

60. Laridan E, Martinod K, De Meyer SF. Neutrophil extracellular traps in arterial and venous thrombosis. Semin Thromb Hemost. 2019;45(1):8693. doi: 10.1055/s-0038-1677040. [PubMed:30634198].

61. Lominadze G, Powell DW, Luerman GC, Link AJ, Ward RA, McLeish KR. Proteomic analysis of human neutrophil granules. Mol Cell Proteomics. 2005;4(10):1503-21. doi: 10.1074/mcp.M500143-MCP200. [PubMed: 15985654].

62. Bonaventura A, Montecucco F, Dallegri F, Carbone F, Luscher TF, Camici GG, et al. Novel findings in neutrophil biology and their impact on cardiovascular disease. Cardiovasc Res. 2019;115(8):1266-85. doi: 10.1093/cvr/cvz084. [PubMed: 30918936].

63. Strecker JK, Schmidt A, Schabitz WR, Minnerup J. Neutrophil granulocytes in cerebral ischemia - Evolution from killers to key players. $\mathrm{Neu}$ rochem Int. 2017;107:117-26. doi:10.1016/j.neuint.2016.11.006. [PubMed: 27884770].

64. Vargas A, Roux-Dalvai F, Droit A, Lavoie JP. Neutrophil-derived exosomes: A new mechanism contributing to airway smooth muscle remodeling. Am J Respir Cell Mol Biol. 2016;55(3):450-61. doi: 10.1165/rcmb.2016-0033OC. [PubMed: 27105177].

65. Feinberg MW, Moore KJ. MicroRNA regulation of atherosclerosis. Circ Res. 2016;118(4):703-20. doi: 10.1161/CIRCRESAHA.115.306300. [PubMed: 26892968]. [PubMed Central: PMC4762069].

66. Gomez I, Ward B, Souilhol C, Recarti C, Ariaans M, Johnston J, et al. Neutrophil microvesicles drive atherosclerosis by delivering miR-155 to atheroprone endothelium. Nat Commun. 2020;11(1):214. doi:10.1038/s41467-019-14043-y. [PubMed:31924781].[PubMed Central: PMC6954269].

67. Westerterp M, Fotakis P, Ouimet M, Bochem AE, Zhang H, Molusky MM, et al. Cholesterol efflux pathways suppress inflammasome activation, NETosis, and atherogenesis. Circulation. 2018;138(9):898-
912. doi: 10.1161/CIRCULATIONAHA.117.032636. [PubMed: 29588315] [PubMed Central: PMC6160368].

68. Gao L, Dong Q, Song Z, Shen F, Shi J, Li Y. NLRP3 inflammasome: A promising target in ischemic stroke. Inflamm Res. 2017;66(1):17-24. doi: 10.1007/s00011-016-0981-7. [PubMed: 27576327].

69. Liang X, Xiu C, Liu M, Lin C, Chen H, Bao R, et al. Platelet-neutrophil interaction aggravates vascular in $\mathrm{fl}$ ammation and promotes the progression of atherosclerosis by activating the TLR4/NF-kappaB pathway. J Cell Biochem. 2019;120(4):5612-9. doi: 10.1002/jcb.27844. [PubMed: 30302814].

70. Bakogiannis C, Sachse M, Stamatelopoulos K, Stellos K. Plateletderived chemokines in inflammation and atherosclerosis. Cytokine. 2019;122:154157. doi:10.1016/j.cyto.2017.09.013. [PubMed: 29198385].

71. Pircher J, Engelmann B, Massberg S, Schulz C. Platelet-neutrophil crosstalk in atherothrombosis. Thromb Haemost. 2019;119(8):1274-82. doi: 10.1055/s-0039-1692983. [PubMed: 31254975].

72. Egan K, Ni Ainle F, Kenny D. Platelets, atherothrombosis, and atherosclerosis. PeerJ Preprints. 2016;4. e2586v1. doi: 10.7287/peerj.preprints.2586v1.

73. Chatterjee M, Gawaz M. Platelets in Atherosclerosis. In: Gresele P, Kleiman N, Lopez J, Page C, editors. Platelets in thrombotic and nonthrombotic disorders. Switzerland: Springer, Cham; 2017. p. 993-1013.

74. Gistera A, Hansson GK. The immunology of atherosclerosis. Nat Rev Nephrol. 2017;13(6):368-80. doi: 10.1038/nrneph.2017.51. [PubMed: 28392564].

75. Place DE, Kanneganti TD. Recent advances in inflammasome biology. Curr Opin Immunol. 2018;50:32-8. doi: 10.1016/j.coi.2017.10.011. [PubMed: 29128729]. [PubMed Central: PMC5857399].

76. Jo EK, Kim JK, Shin DM, Sasakawa C. Molecular mechanisms regulating NLRP3 inflammasome activation. Cell Mol Immunol.2016;13(2):14859. doi: 10.1038/cmi.2015.95. [PubMed: 26549800]. [PubMed Central: PMC4786634]. 